are excellent. The ecologist Mr. Ken Tinley, whose wife is also a biology graduate, has an able assistant.

Last year the Government decided to create a new reserve, to be called Banyine, some hundreds of miles to the south near Laurenço Marques. It will be 80 square miles, and cover every type of terrain from kopje to mangrove, and include some species unknown or scarce in Gorongoza - giraffe, roan, sessaby and cheetah with dudong and turtles on the foreshore.

\title{
The Somali Wild Ass
}

The need to create a reserve for the Somali wild ass Equus asinus somalicus in Ethiopia is urgent, reports Dr Hans Klingel, who has completed his survey, described in the last Oryx, page 6. Dr Klingel has found more animals than expected, but their situation is far from secure. The major threat comes from the Afar people and their large herds of domestic animals. In the rainy season the wild asses can subsist in the desert, but in the dry season they need the water of the Awash River and the few permanent springs. It is therefore essential that the uninhabited Teo area, at present a noman's land between the Afar and Issa tribes, should be declared a wildlife reserve for the asses before either or both of these nomadic tribes decide to graze stock there, a move that may be precipitated by the building of the AwashTendaho highway now going on right through the Teo area. This might lead these nomadic people to change their migration. pattern, and the road might easily become accepted as a boundary between their grazing lands. Even in the rainy season the vegetation here is very sparse, and the wild asses could not successfully compete with stock, quite

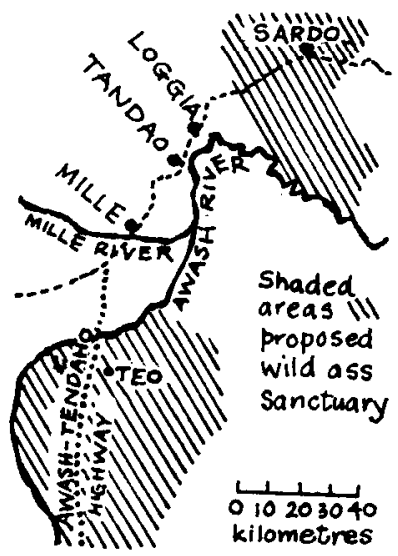
apart from being exposed to the firearms of both tribes who value their meat. The other main concentration of the wild asses, some $70 \mathrm{kms}$ to the north-east, and north of the Awash River, has to contend in addition with some hunting and, much more serious, with tourists, whose chasing of the animals in vehicles in order to get photographs is believed to be a major cause of mortality through exhaustion. Dr Klingel recommends a reserve of about 2800 square $\mathrm{kms}$ in the Teo area, with Afar game guards under an Ethiopian warden to enforce the game laws, and notices (in Amharic, English and Italian) warning visitors that chasing any wild animals by vehicles is illegal and could mean confiscation of the vehicle. 